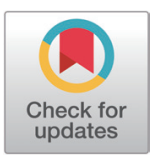

Received: Dec 21, 2021

Revised: Jan 10, 2022

Accepted: Jan 10, 2022

\#These authors contributed equally to this work.

*Corresponding author

Jung Min Heo

Department of Animal Science and

Biotechnology, Chungnam National

University, Daejeon 34134, Korea.

Tel: +82-42-821 5777

E-mail: jmheo@cnu.ac.kr

Jiseon Son

Poultry Research Institute, National

Institute of Animal Science, Rural

Development Administration,

Pyeongchang 25342, Korea.

Tel: +82-33-330-9560

E-mail: wltjs1206@korea.kr

Copyright $(\odot) 2022$ Korean Society of Animal Sciences and Technology.

This is an Open Access article distributed under the terms of the Creative Commons Attribution

Non-Commercial License (http:// creativecommons.org/licenses/by$\mathrm{nc} / 4.0 /$ ) which permits unrestricted non-commercial use, distribution, and reproduction in any medium, provided the original work is properly cited.

ORCID

Yu Bin Kim

https://orcid.org/0000-0001-7720-128X Shan Randima Nawarathne

https://orcid.org/0000-0001-9055-9155 Hyun Min Cho

https://orcid.org/0000-0002-9329-8824

\section{Feeding a calcium-enriched fatty acid could ameliorate the growth performance of broilers under the chronic heat stress}

\author{
Yu Bin Kim ${ }^{1 \#}$, Shan Randima Nawarathne ${ }^{1 \#}$, Hyun Min Cho", \\ Jun Seon Hong ${ }^{1}$, Jung Min Heo ${ }^{1 *}$ and Jiseon Son ${ }^{1,2 *}$ \\ ${ }^{1}$ Department of Animal Science and Biotechnology, Chungnam National University, Daejeon 34134, Korea \\ ${ }^{2}$ Poultry Research Institute, National Institute of Animal Science, Rural Development Administration, \\ Pyeongchang 25342, Korea
}

\section{Abstract}

The current study was conducted to evaluate the effect of calcium-enriched fatty acid supplementation on the growth performance, blood metabolites, intestinal morphology, carcass traits, and nutrient digestibility of broilers subjected to chronic heat stress. A total of 210 oneday-old broiler chicks ( $40.12 \pm 0.25 \mathrm{~g}$ ) were randomly allocated to one of five dietary treatments, to obtain six replicates per treatment. Broilers were subjected to chronic heat stress from day 21 to day 35 , post-hatching, at $34^{\circ} \mathrm{C}$ for $9 \mathrm{~h}$ per day. The body weight (BW) and feed intake of the experimental broilers were recorded weekly, and the average daily gain (ADG) and feed conversion ratio (FCR) were calculated accordingly. Rectal temperature was measured to compare the basal body temperatures between individuals, and blood samples were collected on days 21 and 35 to evaluate basal body temperature, serum total cholesterol, and the triglyceride content of the broilers. On days 21 and 35, one broiler from each cage $(n=6)$ was euthanized to measure carcass trait parameters, nutrient digestibility in digesta, and intestinal morphology. On days 14,28 , and 35 , the broilers fed $2.0 \%$ calcium-enriched fatty acids had higher BW $(p<0.05)$ than those fed the other diets. However, no differences $(p>$ $0.05)$ were found in the average daily feed intake (ADFI) between dietary treatments over the 35 experimental days. On the other hand, on day 21 , post-hatching, the broilers fed the $2.0 \%$ calcium-enriched fatty acid diet had improved $(p<0.05)$ dietary feed efficiencies compared to the other treatments. On day 28 , the broilers fed the $5.0 \%$ of calcium-enriched fatty acid diet also had higher $(p<0.05)$ dietary feed efficiencies than those fed with the other dietary treatments. No effects $(p>0.05)$ on carcass weight, nutrient digestibility, intestinal morphology, or blood parameters were found between broilers fed with dietary treatments. This study demonstrated that the inclusion of an additive, containing $2.0 \%$ calcium-enriched fatty acid, to broiler diet could ameliorate the negative growth performance of broilers; and no interaction $(p>0.05)$ was observed between the calcium-enriched fatty acid and nutrient digestibility, digestive anatomy, blood metabolism, and carcass traits of broilers subjected to chronic heat stress conditions for 35 days post-hatching.

Keywords: Broiler, Calcium-enriched fatty acid, Chronic heat stress, Digestibility, Growth performance 
Jun Seon Hong

https://orcid.org/0000-0003-2142-9888

Jung Min Heo

https://orcid.org/0000-0002-3693-1320

Jiseon Son

https://orcid.org/0000-0002-5285-8186

Competing interests

No potential conflict of interest relevant to this article was reported.

\section{Funding sources}

The authors are grateful to Young Soo Ltd, (Pocheon, Korea) for the financial support and the donation of calcium-enriched fatty acid additive in this study and the paper was financially supported by the research fund of National Institute of Animal Science (PJ016216)

\section{Acknowledgements}

The authors are grateful to Young Soo Ltd, (Pocheon, Korea) for the financial support and the donation of calcium-enriched fatty acid additive in this study.

Availability of data and material Upon reasonable request, the datasets of this study can be available from the corresponding author.

\section{Authors' contributions}

Conceptualization: Heo JM, Son J.

Data curation: Kim YB, Heo JM.

Formal analysis: Kim YB, Heo JM.

Methodology: Kim YB, Heo JM, Son J.

Software: Kim YB, Nawarathne SR

Validation: Kim YB, Nawarathne SR, Heo

JM.

Investigation: Kim YB, Nawarathne SR, Cho HM, Hong JS.

Writing - original draft: Kim YB, Nawarathne SR.

Writing - review \& editing: Kim YB, Nawarathne SR, Cho HM, Hong JS, Heo JM, Son J.

Ethics approval and consent to participate The complete experimental procedure was prior approved by the animal ethics committee of the Chungnam National University, Korea (Protocol No. 201909CNU-118).

\section{INTRODUCTION}

Heat challenges and suboptimal thermal conditions critically affect broiler chickens $[1,2]$, because they are not be able to control their body heat by sweating, as they possess few sweat glands in their skin and a thick layer of insulating feathers over their body [3]. Broilers thermoregulate their bodies by panting, which produces evaporative cooling in their respiratory tract [4]. High temperatures above $30^{\circ} \mathrm{C}$ can lead to heat stress syndrome in broilers [3,5], and heat-stressed broilers exhibit low feed intake, weight gain, and high feed conversion ratios (FCRs) [6-8].

The calcium-enriched fatty acid is an additive composed of protective fat, that gets absorbed in the small intestine without first decomposing within the stomach of an animal; it helps to produce high efficiency growth performance in livestock.

The inclusion of crystalline fat to broiler diets, which protects their intestines, has become a means to not only to boost the energy content of feed in tropical regions but to also reduce specific dynamic action, which helps broilers survive heat stress and avoid growth depression [6,9]. In addition, a previous study [10] reported that a diet containing $5 \%$ more fatty acid than a commercial control diet could reduce the negative effect of heat stress in broilers reared at $29^{\circ} \mathrm{C}-36^{\circ} \mathrm{C}$ by reducing heat production in the body; suggesting that fatty acids induce lower heat production than carbohydrates or proteins because the high energy content of fat (i.e., carbohydrate: $4 \mathrm{kcal} /$ $\mathrm{g}$, protein: $4 \mathrm{kcal} / \mathrm{g}$, fat: $9 \mathrm{kcal} / \mathrm{g}$ ) can reduce metabolic activity. The reduction of feed intake is the most important response (factor) in heat-stressed broilers, because a bird's natural response to heat stress is to lower its heat production [11]. However, [12] reported that increasing dietary density by replacing the calories from carbohydrates with that from fat did not result in the expected $10 \%$ decrease in feed intake in either a hot or cool environment. They emphasized that diets with high ratios of fat can enhance the metabolizable intake energy of broilers by replacing the calories from carbohydrates with those from fat. Other research has also been conducted to evaluate the mortality of heat-stressed broilers, in which $33 \%$ of their metabolizable energy (ME) was supplied by dietary fat; they consumed $10 \%$ more ME and 10\% more protein, and gained $9 \%$ more weight than chicks fed a low-fat ratio diet [13].

The purpose of this study was to investigate the effects of calcium-enriched fatty acid broiler diets on broiler growth performance, blood metabolites, intestinal morphology, and nutrient digestibility under chronic heat stress conditions. We hypothesized that feeding broilers a diet with calciumenriched fatty acids would improve productivity, intestinal architecture, and nutrient digestibility over those fed a standard diet; and thus, also enhance the growth performance of heat-stressed broilers.

\section{MATERIALS AND METHODS}

All procedures were approved, and birds were cared for according to the guidelines of the Animal Care and Use Committee (Protocol No. 201909-CNU-118), Chungnam National University, Korea.

\section{Experimental design and management}

The current study was conducted at the research facility of the Chungnam National University, Republic of Korea. A total of 210 one-day-old "Ross 308" broiler chicks were obtained from a commercial hatchery and randomly distributed to one of five dietary treatments with six replicates for 35 days. Seven birds with similar initial body weight (BW) of $40.12 \pm 0.25 \mathrm{~g}$ (Mean \pm SEM) were allocated in raised wire floor cages $\left(76 \times 61 \times 46 \mathrm{~cm}^{3}\right)$. 
The experimental diets were provided on an ad-libitum basis using metal feed troughs and birds had free access to fresh clean drinking water via nipple drinkers throughout the experiment. Lighting was continuous and the ambient temperature was maintained $30 \pm 1{ }^{\circ} \mathrm{C}$ from day $1-3$ post-hatch and gradually decreased until $25 \pm 1^{\circ} \mathrm{C}$ on day 25 . All the management practices were followed by the guidelines of the Ross broiler management handbook [14].

\section{Experimental diets}

A basal diet (see Table 1) was formulated based on the corn and soybean meal to meet or exceed the nutrient requirements specified in the Ross 308 Nutrition Specification [14]. All the diets were produced in mash form.

The commercial additive of calcium-enriched fatty acid "Yulac" which is ruminant-insoluble fat in the form of bed crystals that are specially bound with fat and calcium salts and help to improve the growth performance of ruminants especially the cows provided from Young Soo Ltd. (Pocheon, Korea) and added as a top dressing to the experimental diets. The feeding regimens were: (1) CON (control; basal diet without calcium-enriched fatty acid), (2) basal diet $+0.5 \%$ calcium-enriched fatty acid), (3) basal diet $+1.0 \%$ of calcium-enriched fatty acid), (4) basal diet $+2.0 \%$ of calciumenriched fatty acid) and (5) basal diet $+5.0 \%$ of calcium-enriched fatty acid. In the whole diet, $0.3 \%$ of chromium oxide $\left(\mathrm{Cr}_{2} \mathrm{O}_{3}:>99.9 \%\right.$, Sigma-Aldrich, St. Louis, MO, USA) was added as an indirect marker for digestibility analysis. Diet samples for chemical analysis were obtained after the mixing.

\section{A procedure of chronic heat stress}

On day 21 post-hatch, all broilers were subjected to chronic heat stress until day 35 post-hatch as follows. The temperature was gradually raised from $25 \pm 1^{\circ} \mathrm{C}$ to $34 \pm 1^{\circ} \mathrm{C}$ over $2 \mathrm{~h}(08: 00 \mathrm{~h}$ to 10:00 h) and maintained at $34 \pm 1{ }^{\circ} \mathrm{C}$ for $9 \mathrm{~h}(10: 00 \mathrm{~h}$ to 19:00 h). Afterward, the temperature was gradually returned to $25 \pm 1^{\circ} \mathrm{C}$ within $1 \mathrm{~h}(19: 00 \mathrm{~h}$ to $20: 00 \mathrm{~h})$ then maintained at $25 \pm 1^{\circ} \mathrm{C}$ for 12 $\mathrm{h}(20: 00 \mathrm{~h}$ to $08: 00 \mathrm{~h})$. The relative humidity was maintained range between $60 \%-70 \%$ during the heat stress period.

\section{Measurements}

Initial BW of the birds were recorded (pen basis) on day 1 of the experiment. Thereafter, the BW of birds was measured weekly (day 7,14,21, 28, and 35) until the end of the experiment and the average daily gain $(\mathrm{ADG})$ of birds on each replicate was calculated. Subsequently, feed intake of each replicate was measured weekly as feed disappearance in the feeder and the average daily feed intake (ADFI) of birds was determined. With the usage of this data, the FCR of birds was calculated in each replicate from day 1-35 post-hatch every week. The mortality of birds was recorded when the death occurred.

\section{Sample collection and post-mortem of birds}

All the samples were collected on days 21 and 35 of the experiment. The deep body temperature of birds was measured by inserting a thermistor probe (FlashCheck ${ }^{\circledR}$ tip probe thermometer, Weber Scientific, Hamilton, NJ, USA) into the birds' rectum. Furthermore, one bird from each pen with the mean BW was selected and blood samples were collected from the jugular vein and carotid artery into spray-coated K2 EDTA vacutainer tubes (BD Vacutainer ${ }^{\circledR}$, Franklin Lakes, NJ, USA). The blood samples were sent to the laboratory for plasma separation. Thereafter, selected birds were euthanized by cervical dislocation, and the ileum samples between Meckel's diverticulum and the ileocecal junction [15] were collected through the cut made in the abdomen of the bird. 
Table 1. Composition ( $\mathrm{g} / \mathrm{kg}$, as-fed basis) of the experimental diets

\begin{tabular}{|c|c|c|}
\hline Ingredients & Day 1-21 & Day 22-35 \\
\hline Corn & 48.51 & 60.96 \\
\hline Wheat & 8.40 & 4.12 \\
\hline Wheat bran & 4.10 & - \\
\hline Soybean meal $48 \%$ & 31.15 & 27.62 \\
\hline Vegetable oil & 3.30 & 3.30 \\
\hline Limestone & 1.20 & 0.95 \\
\hline Mono-calcium phosphate & 1.65 & 1.39 \\
\hline lodized alt & 0.30 & 0.35 \\
\hline Vitamin-mineral premix ${ }^{11}$ & 0.30 & 0.30 \\
\hline Lysine-HCl & 0.34 & 0.30 \\
\hline DL-Methionine & 0.20 & 0.19 \\
\hline L-Threonine & 0.13 & 0.11 \\
\hline L-Cystine & 0.12 & 0.11 \\
\hline Chromium oxide & 0.30 & 0.30 \\
\hline \multicolumn{3}{|l|}{ Calculated values $^{2)}$} \\
\hline Metabolizable energy (kcal/kg) & 3,050 & 3,200 \\
\hline Crude protein (\%) & 22 & 20 \\
\hline $\mathrm{Ca}(\%)$ & 0.90 & 0.80 \\
\hline Available P (\%) & 0.40 & 0.40 \\
\hline Lysin (\%) & 1.39 & 1.24 \\
\hline Methionine (\%) & 0.52 & 0.49 \\
\hline Methionine + cysteine (\%) & 0.88 & 0.82 \\
\hline Threonine (\%) & 0.90 & 0.81 \\
\hline Tryptophan (\%) & 0.25 & 0.22 \\
\hline Valine (\%) & 0.97 & 0.89 \\
\hline Arginine (\%) & 1.34 & 1.19 \\
\hline \multicolumn{3}{|l|}{ Calculated values (SID) } \\
\hline Lysin (\%) & 1.25 & 1.12 \\
\hline Methionine (\%) & 0.48 & 0.46 \\
\hline Methionine + cysteine $(\%)$ & 0.80 & 0.74 \\
\hline Threonine (\%) & 0.78 & 0.71 \\
\hline Tryptophan (\%) & 0.22 & 0.20 \\
\hline Isoleucine (\%) & 0.76 & 0.69 \\
\hline Leucine (\%) & 1.54 & 1.48 \\
\hline Valine (\%) & 0.85 & 0.78 \\
\hline Histidine (\%) & 0.50 & 0.45 \\
\hline Arginine (\%) & 1.22 & 1.07 \\
\hline
\end{tabular}

1)Provided per kilogram of diet: vitamin $\mathrm{A}, 12,000 \mathrm{IU}$; vitamin $\mathrm{D}_{3}, 2,500 \mathrm{IU}$; vitamin $\mathrm{E}, 30 \mathrm{IU}$; vitamin $\mathrm{K}_{3}, 3 \mathrm{mg}$; D-pantothenic acid, $15 \mathrm{mg}$; nicotinic acid, $40 \mathrm{mg}$; choline, $400 \mathrm{mg}$; and vitamin $\mathrm{B}_{12}, 12 \mu \mathrm{g}$; Fe, $90 \mathrm{mg}$ from iron sulfate; $\mathrm{Cu}, 8.8 \mathrm{mg}$ from copper sulfate; $\mathrm{Zn}, 100 \mathrm{mg}$ from zinc oxide; $\mathrm{Mn}, 54 \mathrm{mg}$ from manganese oxide; I, $0.35 \mathrm{mg}$ from potassium iodide; $\mathrm{Se}, 0.30 \mathrm{mg}$ from sodium selenite.

${ }^{2}$ The values were calculated according to the values of feedstuffs in NRC [16] and Ross 308 Broiler Nutrition Specification [14]. SID, standardized ileal digestibility. 
Approximately, a $3 \mathrm{~cm}$ part of ileum samples were washed inner and outer areas by phosphate buffer saline (PBS) at $\mathrm{pH}$ 7.4. Cleaned samples were immediately stored in the $10 \%$ neutral buffered formaldehyde (Sigma Chemical, St. Louis, MO) for fixation before the mucosa architecture analysis. The remaining digesta in each ileum was collected and stored at $-20^{\circ} \mathrm{C}$ until to perform nutrient and digestibility analysis. The procedure of collection was conducted according to [17].

Empty BW (without head and shanks), skinless breast meat weight (including pectoralis major and minor), and leg meat weight were obtained separately in each sacrificed bird. All the breast and leg meat weights were expressed in proportion to the carcass weight.

\section{Sample preparation and laboratory analysis}

Blood samples were centrifuged (Micro 12, Hanil Science, Gimpo, Korea) to separate plasma and serum at 3,000×g for 10 minutes at $4^{\circ} \mathrm{C}$. Serum total cholesterol and triglyceride content in the blood were analyzed using Biochemistry Analyzer 7020 (HITACHI, Tokyo, Japan).

Proximate composition in the ileal digesta was determined by using the standard method of [18]. Before analysis, digesta samples were dried at $55^{\circ} \mathrm{C}$ for $24 \mathrm{~h}$ and grounded through a $0.75 \mathrm{~mm}$ sieve (ZM 200 Ultra-Centrifugal Mill, Retsch GmbH \& Co. KG, Haan, Germany). Dry matter content, gross energy, crude protein content ("Kjedhal" method; nitrogen content $\times 6.25$ ), and crude fat content (Soxhlet extraction method) were determined from the finely grounded digesta samples. Furthermore, nutrient digestibility was analyzed by calculating the chromium oxide concentration in digesta samples [19]. The digestibility of nutrients was calculated according to [20] by using the following equation.

$$
\text { Apperent digestibility coeffcient }=1-[(\mathrm{ID}-\mathrm{AF}) /(\mathrm{IF}-\mathrm{AD})]
$$

Where ID denotes the concentration of an indigestible marker in the diet; AF is the nutrient concentration in ileal digesta; IF is the indigestible-marker concentration in ileal digesta; and $\mathrm{AD}$ is the nutrient concentration in the diet.

Sample preparation for ileum morphology analysis was done according to the methodology described by [21] with some modifications. Briefly, ileal tissue samples fixed in $10 \%$ formaldehyde were taken and ring-shaped portions were excised, dehydrated for 16 hours, followed by embedded in paraffin wax. Six transverse sections with 4 to $6 \mu \mathrm{m}$ of thickness were cut from each of these wax cubes and placed on glass slides. Subsequently, glass slides that contained ileal sections were heated at $57^{\circ} \mathrm{C}$ until dry. Afterward, dried slides were stained with hematoxylin and eosin stain besides roofed by another slide. Well-oriented 10 villi and associated 10 crypts were selected for taking villus height and crypt depth measurements using NIS-Elements viewer software (Version: 4.20; NIS Elements, Nikon, Melville, NY, USA) with the aid of calibrated eyepiece of an inverted microscope (Eclipse TE2000, Nikon Instrument, Melville, NY, USA) that had a calibrated eyepiece graticule. Moreover, by using those ileal morphological data, the villus height to crypt depth ratio (V: C) was calculated.

\section{Statistical analyses}

Data were analyzed using the one-way ANOVA, Completely Randomize Design (CRD) by using the SPSS software package (Version 26, IBM, Armonk, NY, USA). Tukey's multiple range test was used to determine the significant differences between experimental groups at a $p<0.05$ significant level. A pen was considered as the experimental unit for growth performance measures and sacrificed birds were used as the experiment units for analyses of the carcass weight, blood metabolism, intestinal morphology, and nutrient digestibility. Moreover, the ratio of calcium- 
enriched fatty acid supplementation was considered as the main effect.

\section{RESULTS}

\section{Growth performance}

All birds remained healthy and performed well; the mortality rate of the birds was not affected by dietary treatments and the mortality rate was below $2 \%$ (four of two-hundred and ten birds) during the total experimental period. The heat-eliminating behaviors of the broilers were observed frequently during the chronic heat stress period.

The effects of enriching broiler diets with calcium-enriched fatty acid feed additives on the growth performance of broilers under chronic heat stress conditions, from days 1-35 (posthatching) are summarized in Table 2. Broilers fed $2.0 \%$ of the calcium-enriched fatty acid diet had improved $(p<0.05)$ BW compared to broilers fed control (CON) diets on day 14. However, on days 14,28 , and 35 (post-hatching), broilers fed the $5.0 \%$ calcium-enriched fatty acid diet showed lower $(p<0.05)$ BW than broilers fed the $2.0 \%$ calcium-enriched fatty acid diet. Similarly, broilers fed the $5.0 \%$ calcium-enriched fatty acid diet showed reduced $(p<0.05)$ ADG on day 28 posthatching and during the overall experimental period, compared to those fed the other dietary treatments. Moreover, no dietary treatment effect $(p>0.05)$ was observed on the ADFI of broilers at 35 days post-hatching. Interestingly, birds fed the $2.0 \%$ calcium-enriched fatty acid diet showed improved $(p<0.05)$ FCR during the initial period (1-21 days), compared to the other treatments; except for broilers fed the $1.0 \%$ calcium-enriched fatty acid diet.

\section{Rectal temperature}

The effect of calcium-enriched fatty acids on the rectal temperatures of broilers under chronic heat stress at 35 days, post-hatching, are presented in Table 3. Broilers fed the 5.0\% calcium-enriched fatty acid diet showed lower rectal temperatures on day 21, post-hatching, than those of the heat-treatment broilers fed the $0.5 \%$ and $2.0 \%$ calcium-enriched fatty acid diet. Nonetheless, no interactions $(p>0.05)$ were observed between the calcium-enriched fatty acid supplementation and rectal temperatures on day 35 day old broilers.

\section{Main factors of the euthanized bird}

The effects of calcium-enriched fatty acid inclusion on carcass weight, nutrient digestibility, intestinal morphology, and blood parameters of heat-stressed broilers are presented in Tables 4, 5, 6, and 7 . There were no dietary effects $(p>0.05)$ of the calcium-enriched fatty acid supplementation to broilers under chronic heat stress conditions, on the main characteristics of the euthanized birds on days 21 and 35 post-hatching.

\section{DISCUSSION}

It is a strong belief that climate conditions, especially hot weather, are the most significant factors limiting production in the poultry industry. [22] stated that negative effects of heat stress on animals include reduced growth, reproduction performance, and poor carcass traits. Previous studies by $[6,12,23]$ reported decrements of $49 \%-67 \%$ in the growth rate ratios of broilers subjected to chronic heat stress, due to corresponding reductions in feed intake. In addition, [24] concluded that the observed reductions in the growth performance of broilers under heat stress conditions could be attributed to a large amount of energy being wasted in adapting to high temperatures. Moreover, the excretion of digestible minerals in broilers under ambient temperatures higher than $24^{\circ} \mathrm{C}$ 
Table 2. Effect of calcium-enriched fatty acid along with chronic heat stress on growth performance in broilers ${ }^{1)}$

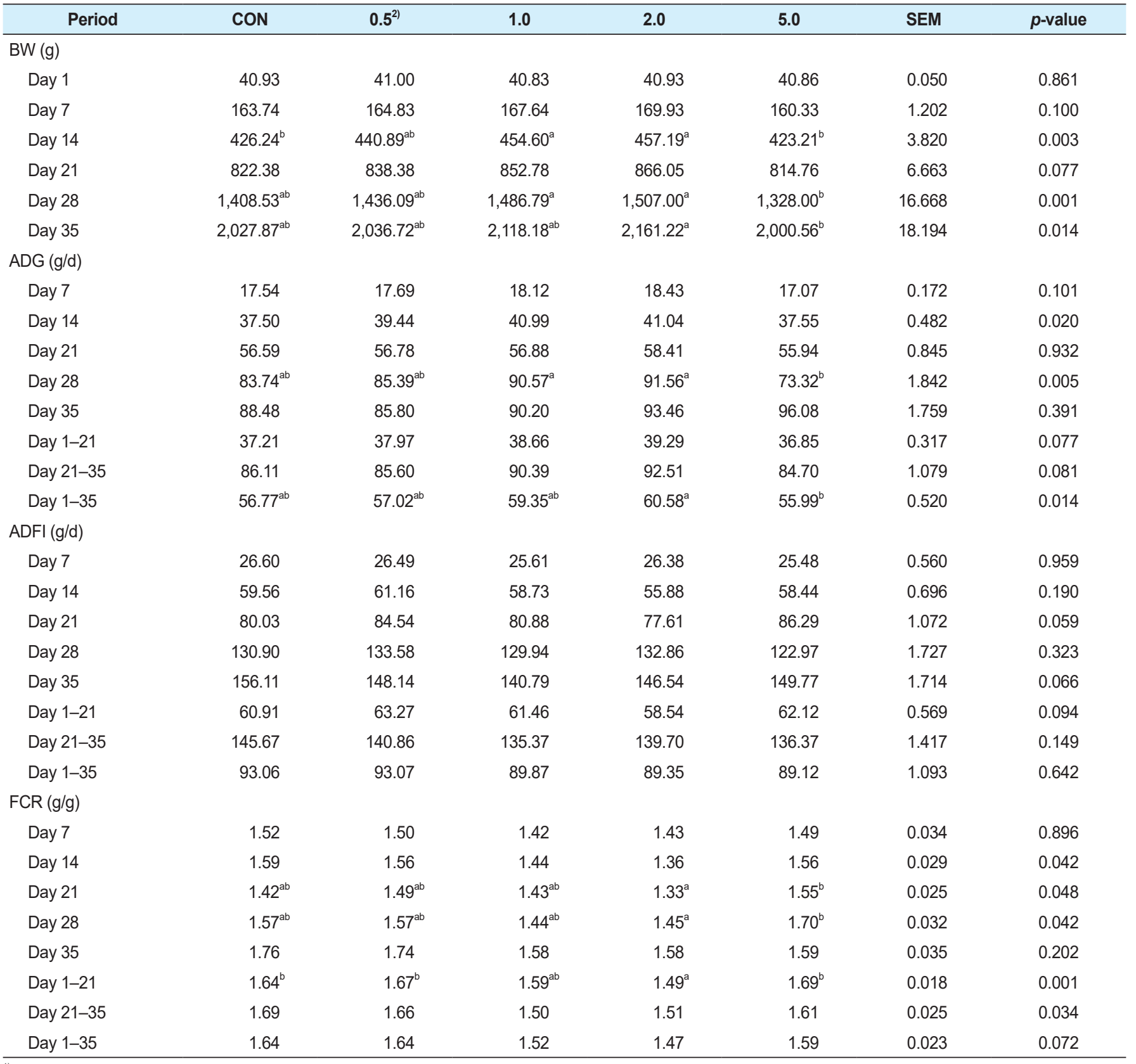

${ }^{1)}$ Values are the mean of six replicates per treatment.

${ }^{2)}$ The ratio of additive of calcium-enriched fatty acid in diets.

${ }^{a, b}$ Values in a row with different superscripts differ significantly $(p<0.05)$.

Con, control diet; SEM, pooled standard error of mean; BW, body weight; ADG, average daily gain; ADFI, average daily feed intake; FCR, feed conversion ratio.

Table 3. Effects of calcium-enriched fatty acid on the rectal temperature in broilers ${ }^{1)}$

\begin{tabular}{cccccccc}
\hline \multicolumn{1}{c}{ Period } & CON & $\mathbf{0 . 5 ^ { 2 }}$ & $\mathbf{1 . 0}$ & $\mathbf{2 . 0}$ & $\mathbf{5 . 0}$ & SEM & $\boldsymbol{p}$-value \\
\hline Day 21 & $40.62^{\mathrm{ab}}$ & $40.77^{\mathrm{b}}$ & $40.66^{\mathrm{ab}}$ & $40.75^{\mathrm{b}}$ & $40.52^{\mathrm{a}}$ & 0.025 & 0.009 \\
Day 35 & 40.74 & 40.79 & 40.72 & 40.82 & 40.84 & 0.035 & 0.780 \\
\hline
\end{tabular}

${ }^{11}$ Values are the mean of six replicates per treatment.

${ }^{2)}$ The ratio of additive of calcium-enriched fatty acid in diets.

a,b Values in a row with different superscripts differ significantly $(p<0.05)$.

Con, control diet; SEM, pooled standard error of mean. 
Table 4. Effects of calcium-enriched fatty acid on carcass weight in broilers ${ }^{1)}$

\begin{tabular}{|c|c|c|c|c|c|c|c|}
\hline Period & CON & $0.5^{2)}$ & 1.0 & 2.0 & 5.0 & SEM & $p$-value \\
\hline \multicolumn{8}{|c|}{ Empty body weight (\%) } \\
\hline Day 21 & 88.33 & 88.06 & 87.92 & 88.55 & 87.28 & 0.173 & 0.177 \\
\hline \multicolumn{8}{|l|}{ Drumstick $^{3)}(\%)$} \\
\hline Day 21 & 9.41 & 9.07 & 9.08 & 9.06 & 9.12 & 0.093 & 0.751 \\
\hline Day 21 & $22.45^{\mathrm{ab}}$ & $24.68^{b}$ & $23.53^{\mathrm{ab}}$ & $22.76^{a}$ & $22.30^{\mathrm{a}}$ & 0.304 & 0.066 \\
\hline Day 35 & 25.55 & 26.85 & 27.01 & 27.07 & 27.11 & 0.360 & 0.640 \\
\hline
\end{tabular}

${ }^{11}$ Values are the mean of six replicates per treatment.

${ }^{2)}$ The ratio of additive of calcium-enriched fatty acid in diets.

${ }^{3}$ Drumstick and breast meat weights were expressed in proportion to the carcass weight.

Con, control diet; SEM, pooled standard error of mean.

Table 5. Effects of calcium-enriched fatty acid on nutrient digestibility in broilers ${ }^{1)}$

\begin{tabular}{|c|c|c|c|c|c|c|c|}
\hline Period & CON & $0.5^{2)}$ & 1.0 & 2.0 & 5.0 & SEM & $p$-value \\
\hline \multicolumn{8}{|l|}{ Dry matter (\%) } \\
\hline Day 21 & 78.1 & 78.9 & 80.0 & 78.7 & 77.1 & 0.38 & 0.476 \\
\hline Day 35 & 80.5 & 80.0 & 79.9 & 79.3 & 81.5 & 0.51 & 0.532 \\
\hline \multicolumn{8}{|l|}{ Crude protein (\%) } \\
\hline Day 21 & 66.6 & 67.1 & 69.3 & 69.1 & 68.2 & 0.58 & 0.490 \\
\hline Day 35 & 69.6 & 69.7 & 70.4 & 69.5 & 65.5 & 1.17 & 0.551 \\
\hline \multicolumn{8}{|l|}{ Crude fat $(\%)$} \\
\hline Day 21 & 66.0 & 66.5 & 67.3 & 68.4 & 66.6 & 0.71 & 0.848 \\
\hline Day 35 & 66.1 & 66.6 & 65.7 & 65.9 & 66.4 & 0.45 & 0.969 \\
\hline \multicolumn{8}{|l|}{ Energy (\%) } \\
\hline Day 21 & 75.6 & 76.3 & 77.5 & 77.6 & 76.5 & 0.58 & 0.818 \\
\hline Day 35 & 78.9 & 79.5 & 79.7 & 77.6 & 79.7 & 0.44 & 0.538 \\
\hline
\end{tabular}

${ }^{1)}$ Values are the mean of six replicates per treatment.

${ }^{2}$ The ratio of additive of calcium-enriched fatty acid in diets.

Con, control diet; SEM, pooled standard error of mean.

Table 6. Effects of calcium-enriched fatty acid on intestinal morphology in broilers ${ }^{1)}$

\begin{tabular}{|c|c|c|c|c|c|c|c|}
\hline Period & CON & $0.5^{2)}$ & 1.0 & 2.0 & 5.0 & SEM & $p$-value \\
\hline \multicolumn{8}{|l|}{ Day 21} \\
\hline Villous height $(\mu \mathrm{m})$ & 366.0 & 374.5 & 378.1 & 387.4 & 364.7 & 4.06 & 0.400 \\
\hline Crypt depth ( $\mu \mathrm{m})$ & 57.7 & 58.3 & 58.0 & 58.2 & 58.2 & 0.31 & 0.908 \\
\hline $\mathrm{V}: \mathrm{C}$ ratio $^{3)}$ & 6.3 & 6.4 & 6.5 & 6.7 & 6.2 & 0.07 & 0.347 \\
\hline \multicolumn{8}{|l|}{ Day 35} \\
\hline Villous height $(\mu \mathrm{m})$ & 461.4 & 447.4 & 474.7 & 452.4 & 455.0 & 3.97 & 0.260 \\
\hline Crypt depth $(\mu \mathrm{m})$ & 76.3 & 77.4 & 77.3 & 76.8 & 75.6 & 0.38 & 0.537 \\
\hline V:C ratio & 6.1 & 5.8 & 6.1 & 5.9 & 6.0 & 0.07 & 0.455 \\
\hline
\end{tabular}

${ }^{1)}$ Values are the mean of six replicates per treatment.

${ }^{2)}$ The ratio of additive of calcium-enriched fatty acid in diets.

${ }^{3}$ Values are the mean of villous height divided by crypt depth.

Con, control diet; SEM, pooled standard error of mean. 
Table 7. Effects of calcium-enriched fatty acid on blood parameters in broilers ${ }^{1)}$

\begin{tabular}{|c|c|c|c|c|c|c|c|}
\hline Period & CON & $0.5^{2)}$ & 1.0 & 2.0 & 5.0 & SEM & $p$-value \\
\hline \multicolumn{8}{|l|}{ Day 21} \\
\hline Total cholesterol (mg/dL) & 95.3 & 96.1 & 98.5 & 99.9 & 98.7 & 0.76 & 0.311 \\
\hline \multicolumn{8}{|l|}{ Day 35} \\
\hline Total cholesterol (mg/dL) & 91.8 & 96.1 & 97.4 & 95.0 & 94.7 & 0.92 & 0.373 \\
\hline
\end{tabular}

${ }^{1)}$ Values are the mean of six replicates per treatment.

${ }^{2)}$ The ratio of additive of calcium-enriched fatty acid in diets.

Con, control diet; SEM, pooled standard error of mean.

which was potentially a cause of nutritional imbalance [25]. Therefore, preventing heat stress in broilers, which causes them to have reduced productivity and nutritional imbalances, is an essential requirement.

The present study [26] hypothesized that the inclusion of dietary additives composed of calcium-enriched fatty acids in broiler diets could prevent growth reduction and improve growth performance and immunity in broilers under heat stress conditions. [22] reported that hightemperature stress in broilers increases the lipoprotein lipase levels in their adipose tissue, which improves their capacity to absorb and store hepatic-derived triglycerides; thus, alterations in their lipid metabolism can improve their energy balance and nutritional condition. This is strong confidence that the high-temperature stress in broilers can be reduced by including calciumenriched fatty acids in their diet. The results of the current study revealed that the supplementation of broiler diets with $2.0 \%$ calcium-enriched fatty acids had a positive influence $(p<0.05)$ on the BW of broilers under chronic heat-stress conditions, as observed on day 14. Our results are in agreement with those of previous studies by [27], who reported that the incorporation of high energy soy and palm oil into the diet of heat-challenged broilers significantly promoted $(p<$ $0.05)$ their growth, due to decreased feed integrity (or "dustiness"), lower increments in body heat production, and improved feed palatability. Similarly, [23] obtained a significant increase $(p<0.05)$ in the $\mathrm{BW}$ of broilers under the chronic heat stress conditions of $26 \pm 2{ }^{\circ} \mathrm{C}$; by increasing energy levels through the incorporation of prebiotics and probiotics to their diets from day 21 to 42 , post-hatching. Furthermore, the current study revealed that the broilers fed a diet comprising 2\% additives showed improved FCR compared to broilers fed CON diets during the starter period (121 days). On the other hand, there were no significant effects on the broilers fed the $5 \%$ calciumenriched fatty acid diet. This was a similar result to those of several studies that fed broilers diets containing low energy; the broilers exhibited high efficiencies in growth performance, in contrast to the broilers fed low energy diets, and it was concluded that a high energy diet prevents the loss of energy in adaptation to high temperatures [27-29]. Consistent with this interpretation, [30] demonstrated that adding a high ratio of fat to broiler diets would improve the metabolic efficiency and reduce their feed intake requirements, leading to reductions in metabolic activity. Additionally, [31] reported that dietary supplementation with rich sources of $n-3$ polyunsaturated fatty acids could have a beneficially modulating influence on broiler immune systems, and it appeared to decrease inflammatory immune reactions and simultaneously improve specific immunity indices.

This study observed the rectal temperature of broilers with a strong confidence in predicting the average body temperature of the birds under high-temperature conditions. The results also revealed an interaction between the ratios of calcium-enriched fatty acids in a diet and the average rectal temperature of broilers at days 21 and 35, post-hatching. Furthermore, it was lower than the rectal 
temperature reported by [32] which found a broiler rectal temperature of $42.57^{\circ} \mathrm{C}$ under heat stress conditions $\left(32^{\circ} \mathrm{C}, 40 \%\right.$ relative humidity). Broilers fed the $5 \%$ calcium-enriched fatty acid diet showed lower rectal temperatures on day 21 compared to broilers fed the $0.5 \%$ and $2.0 \%$ calciumenriched fatty acid diets. It is anticipated that heat generation in the body of broilers can be reduced by including more than a specific amount of calcium-enriched fatty acid additives to their diets.

The proportion of edible meat in an animal body is an index of productive efficiency, and previous studies have focused on increasing broiler meat weight for a long time [33]. Broiler meat is divided into various sections for the commercial market, which favors breast meat; while drumsticks are widely preferred as nutritionally superior foods that contain essential levels of nutrients: carbohydrates, proteins, fats, minerals, and vitamins, along with a specific taste [34,35]. Previous studies have observed a low proportion of breast meat, a high proportion of thigh meat, and reduction of muscle protein synthesis in broiler meat under high-temperature conditions, compared to the standard housing temperature for broilers [36,37]. Contrary to the results of [38], who observed a negative effect on the proportions of broiler meat under heat stress (high-temperature conditions), calcium-enriched fatty acids did not affect carcass proportions; including empty body, breast meat, and drumstick weights of the broilers, from hatching to 35 days of age. However, other studies have reported that the chronic exposure of broilers to a high ambient temperature is highly correlated to increased ratios of abdominal, subcutaneous, and intermuscular fat deposits [39,40]. Our results indicated that chronic heat stress reduced muscle protein, but that the average broiler carcass weight was supplemented with fat deposits.

Contrary to the results of [37], who described the effects of dietary methionine isomers on broilers under acute heat stress conditions, the current study did not find any significant effects on nutrient digestibility, intestinal morphology, and blood parameters. The broilers in this study were fed with calcium-enriched fatty acid additives and subjected to chronic heat stress conditions. Apart from the calcium-enriched fatty acid, the feed fed to the broilers in this study had identical nutrients. [41] concluded that the villi height and ratio between villi heights and crypt depth of broilers could be affected by including the fat from tallow and dietary oil in their diet; however, this study did not find any significant effects of the dietary inclusion of calcium-enriched fatty acids on the intestinal morphology of broilers. Likewise, there were no significant effects on blood parameters due to the inclusion of calcium-enriched fatty acid to broiler diets; contrary to [42], who reported that probiotic supplementation to broilers reduces their serum cholesterol levels.

In conclusion, over the five weeks of the experimental period, broilers fed a diet containing calcium-enriched fatty acid additive showed improved growth performance under chronic heat stress conditions. On the other hand, the inclusion of calcium-enriched fatty acid additives to the diet of broilers did not influence nutrient digestibility, intestinal morphology, and blood parameters of broilers examined on days 21 and 35, post-hatching.

\section{REFERENCES}

1. Altan Ö, Pabuçcuoğlu A, Altan A, Konyalioğlu S, Bayraktar H. Effect of heat stress on oxidative stress, lipid peroxidation and some stress parameters in broilers. Br Poult Sci. 2003;44:545-50. https://doi.org/10.1080/00071660310001618334

2. Lara LJ, Rostagno MH. Impact of heat stress on poultry production. Animals. 2013;3:356-69. https://doi.org/10.3390/ani3020356

3. Park SO, Park BS, Hwangbo J. Effect of cold water and inverse lighting on growth performance of broiler chickens under extreme heat stress.J Environ Biol. 2015;36:865-73.

4. Santos RR, Awati A, Roubos-van den Hil PJ, Tersteeg-Zijderveld MHG, Koolmees PA, Fink- 
Gremmels J. Quantitative histo-morphometric analysis of heat-stress-related damage in the small intestines of broiler chickens. Avian Pathol. 2015;44:19-22. https://doi.org/10.1080/0307 9457.2014.988122

5. Farooqi HAG, Khan MS, Khan MA, Rabbani M, Pervez K, Khan JA. Evaluation of betaine and vitamin C in alleviation of heat stress in broilers. Int J Agric Biol. 2005;7:744-6.

6. Daghir NJ. Nutritional strategies to reduce heat stress in broilers and broiler breeders. Lohmann Inf. 2009;44:6-15.

7. Günal M. The effects of early-age thermal manipulation and daily short-term fasting on performance and body temperatures in broiler exposed to heat stress. J Anim Physiol Anim Nutr. 2013;97:854-60. https://doi.org/10.1111/j.1439-0396.2012.01330.x

8. Mack LA, Felver-Gant JN, Dennis RL, Cheng HW. Genetic variations alter production and behavioral responses following heat stress in 2 strains of laying hens. Poult Sci. 2013;92:285-94. https://doi.org/10.3382/ps.2012-02589

9. Gous RM, Morris TR. Nutritional interventions in alleviating the effects of high temperatures in broiler production. Worlds Poult Sci J. 2005;61:463-75. https://doi.org/10.1079/ WPS200568

10. Ghazalah AA, Abd-Elsamee MO, Ali AM. Influence of dietary energy and poultry fat on the response of broiler chicks to heat therm. Int J Poult Sci. 2008;7:355-9. https://doi.org/10.3923/ ijps.2008.355.359

11. Teeter RG, Belay T. Broiler management during acute heat stress. Anim Feed Sci Technol. 1996;58:127-42. https://doi.org/10.1016/0377-8401(95)00879-9

12. Dale NM, Fuller HL. Effects of diet composition on feed intake and growth of chicks under heat stress: I. dietary fat levels. Poult Sci. 1979;58:1529-34. https://doi.org/10.3382/ps.0581529

13. Daghir NJ. Broiler feeding and management in hot climates. In: Daghir NJ, editor. Poultry production in hot climate. Wallingford: CABI; 2008. p. 227-60.

14. Aviagen. Ross 308 broiler nutrition specifications. Huntsville, AL: Aviagen Group; 2014.

15. Incharoen T, Yamauchi K, Erikawa T, Gotoh H. Histology of intestinal villi and epithelial cells in chickens fed low-crude protein or low-crude fat diets. Ital J Anim Sci. 2010;9:e82. https:// doi.org/10.4081/ijas.2010.e82

16. NRC [National Research Council]. Nutrient requirements of poultry. 9th rev. ed. Washington, DC: National Academies Press; 1994.

17. Wickramasuriya SS, Kim E, Cho HM, Shin TK, Kim B, Lee M, et al. Differential effects of dietary methionine isomers on broilers challenged with acute heat stress. J Poult Sci. 2019;56:195-203. https://doi.org/10.2141/jpsa.0180072

18. Lee J, Durst RW, Wrolstad RE. Determination total monomeric anthocyanin pigment content of fruit juices, beverages, natural colorants, and wines by the $\mathrm{pH}$ differential method: Collaborative Study. J AOAC International. 2005;88:1269-78.

19. Fenton TW, Fenton M. An improved procedure for the determination of chromic oxide in feed and feces. Can J Anim Sci. 1979;59:631-4. https://doi.org/10.4141/cjas79-081

20. Huang RL, Yin YL, Wu GY, Zhang YG, Li TJ, Li LL, et al. Effect of dietary oligochitosan supplementation on ileal digestibility of nutrients and performance in broilers. Poult Sci. 2005;84:1383-8. https://doi.org/10.1093/ps/84.9.1383

21. Pelicano ERL, Souza PA, Souza HBA, Figueiredo DF, Boiago MM, Carvalho SR, et al. Intestinal mucosa development in broiler chickens fed natural growth promoters. Braz J Poult Sci. 2005;7:221-9. https://doi.org/10.1590/S1516-635X2005000400005

22. Baumgard LH, Rhoads RP Jr. Effects of heat stress on postabsorptive metabolism and energetics. Annu Rev Anim Biosci. 2013;1:311-37. https://doi.org/10.1146/annurev-animal-031412-103644 
23. Sohail MU, Hume ME, Byrd JA, Nisbet DJ, Ijaz A, Sohail A, et al. Effect of supplementation of prebiotic mannan-oligosaccharides and probiotic mixture on growth performance of broilers subjected to chronic heat stress. Poult Sci. 2012;91:2235-40. https://doi.org/10.3382/ps.201202182

24. Lei KY, Slinger SJ. Energy utilization in the chick in relation to certain environmental stresses. Can J Anim Sci. 1970;50:285-92. https://doi.org/10.4141/cjas70-043

25. Belay T, Wiernusz CJ, Teeter RG. Mineral balance and urinary and fecal mineral excretion profile of broilers housed in thermoneutral and heat-distressed environments. Poult Sci. 1992;71:1043-7. https://doi.org/10.3382/ps.0711043

26. Bong MH, Ji SY, Park JC, Moon HK, Lee SC, Lee JH, et al. Effect of feeding plum and red ginseng marc on vital reaction in broiler stress. Korean J Poult Sci. 2011;38:213-23. https://doi. org/10.5536/KJPS.2011.38.3.213

27. Zulkifli I, Htin NN, Alimon AR, Loh TC, Hair-Bejo M. Dietary selection of fat by heatstressed broiler chickens. Asian-Australas J Anim Sci. 2007;20:245-51. https://doi.org/10.5713/ ajas. 2007.245

28. Fuller HL, Rendon M. Energetic efficiency of different dietary fats for growth of young chicks. Poult Sci. 1977;56:549-57. https://doi.org/10.3382/ps.0560549

29. Nitsan Z, Dvorin A, Zoref Z, Mokady S. Effect of added soyabean oil and dietary energy on metabolisable and net energy of broiler diets. Br Poult Sci. 1997;38:101-6. https://doi. org/10.1080/00071669708417948

30. Rosebrough RW, McMurtry JP, Vasilatos-Younken R. Dietary fat and protein interactions in the broiler. Poult Sci. 1999;78:992-8. https://doi.org/10.1093/ps/78.7.992

31. Swiatkiewicz S, Arczewska-Wlosek A, Jozefiak D. The relationship between dietary fat sources and immune response in poultry and pigs: an updated review. Livest Sci. 2015;180:237-46. https://doi.org/10.1016/j.livsci.2015.07.017

32. Lin H, Decuypere E, Buyse J. Acute heat stress induces oxidative stress in broiler chickens. Comp Biochem Physiol A Mol Integr Physiol. 2006;144:11-7. https://doi.org/10.1016/ j.cbpa.2006.01.032

33. Jackson S, Summers JD, Leeson S. Effect of dietary protein and energy on broiler performance and production costs. Poult Sci. 1982;61:2232-40. https://doi.org/10.3382/ps.0612232

34. Fanatico AC, Pillai PB, Emmert JL, Owens CM. Meat quality of slow- and fast-growing chicken genotypes fed low-nutrient or standard diets and raised indoors or with outdoor access. Poult Sci. 2007;86:2245-55. https://doi.org/10.1093/ps/86.10.2245

35. Orr HL, Hunt EC, Randall CJ. Yield of carcass, parts, meat, skin, and bone of eight strains of broilers. Poult Sci. 1984;63:2197-200. https://doi.org/10.3382/ps.0632197

36. Temim S, Chagneau AM, Peresson R, Tesseraud S. Chronic heat exposure alters protein turnover of three different skeletal muscles in finishing broiler chickens fed 20 or $25 \%$ protein diets.J Nutr. 2000;130:813-9. https://doi.org/10.1093/jn/130.4.813

37. Yunianto VD, Hayashit K, Kaiwda S, Ohtsuka A, Tomita Y. Effect of environmental temperature on muscle protein turnover and heat production in tube-fed broiler chickens. Br J Nutr. 1997;77:897-909. https://doi.org/10.1079/BJN19970088

38. Zhang ZY, Jia GQ, Zuo JJ, Zhang Y, Lei J, Ren L, et al. Effects of constant and cyclic heat stress on muscle metabolism and meat quality of broiler breast fillet and thigh meat. Poult Sci. 2012;91:2931-7. https://doi.org/10.3382/ps.2012-02255

39. Baziz HA, Geraert PA, Padilha JCF, Guillaumin S. Chronic heat exposure enhances fat deposition and modifies muscle and fat partition in broiler carcasses. Poult Sci. 1996;75:50513. https://doi.org/10.3382/ps.0750505 
40. Geraert PA, Padilha JCF, Guillaumin S. Metabolic and endocrine changes induced by chronic heat exposure in broiler chickens: growth performance, body composition and energy retention. Br J Nutr. 1996;75:195-204. https://doi.org/10.1017/BJN19960124

41. Poorghasemi M, Chamani M, Mirhosseini SZ, Sadeghi AA, Seidavi A. Effect of probiotic and different sources of fat on performance, carcass characteristics, intestinal morphology and ghrelin gene expression on broiler chickens. Kafkas Univ Vet Fak Derg. 2018;24:169-78. https://doi.org/10.9775/kvfd.2017.18433

42. Alkhalf A, Alhaj M, Al-homidan I. Influence of probiotic supplementation on blood parameters and growth performance in broiler chickens. Saudi J Biol Sci. 2010;17:219-25. https://doi.org/10.1016/j.sjbs.2010.04.005 